Check for updates

Cite this: RSC Adv., 2019, 9, 41664

Received 10th November 2019 Accepted 10th December 2019

DOI: $10.1039 / c 9 r a 09352 d$

rsc.li/rsc-advances

\section{Purification strategy and effect of impurities on corrosivity of dehydrated carnallite for thermal solar applications}

\begin{abstract}
Youyang Zhao, (D) * Noah Klammer and Judith Vidal
This paper presents a purification method for dehydrated carnallite (DC) - a commercial ternary $\mathrm{MgCl}_{2}-$ $\mathrm{KCl}-\mathrm{NaCl}$ salt-for concentrating solar power (CSP) applications based on a thermal and chemical treatment using the reduction power of $\mathrm{Mg}$. The purification is effective at reducing $\mathrm{MgOH}^{+}$by an order of magnitude-from around $5 \mathrm{wt} \%$ in non-treated salt to less than $0.5 \mathrm{wt} \%$ in post-purification salt. The corresponding decrease in the measured corrosion rate of Haynes 230 at $800{ }^{\circ} \mathrm{C}$ from $>3200 \mu \mathrm{m}$ per year to around $40 \mu \mathrm{m}$ per year indicates that soluble $\mathrm{MgOH}^{+}$is indeed correlated to corrosion. The addition of elemental $\mathrm{Mg}$ serves as both a scavenger of impurities and corrosion potential control, which are considered the primary mechanisms for corrosion mitigation.
\end{abstract}

\section{Introduction}

To enable the use of a supercritical carbon dioxide $\left(\mathrm{sCO}_{2}\right)$ Brayton power cycle, next-generation (Gen3) concentrating solar power (CSP) requires a heat-transfer fluid (HTF) and thermal energy storage (TES) medium that can operate in the temperature range of $500-750^{\circ} \mathrm{C}$. This operational temperature differs from the current Gen2's molten nitrate HTF and TES medium, which is stable up to $\sim 565{ }^{\circ} \mathrm{C}$. Gen3 CSP's higher operating temperature range demands new chemistry with high thermal stability and low corrosion on metallic materials used in the receiver, primary heat exchangers, piping, and TES tanks.

Dehydrated carnallite (DC)-a commercial ternary $\mathrm{MgCl}_{2}-$ $\mathrm{KCl}-\mathrm{NaCl}$ chloride-salt-has been proposed given its thermal stability up to $\sim 800{ }^{\circ} \mathrm{C}$, low cost, and availability. The liquidus temperature of the DC salt is also around $440-450{ }^{\circ} \mathrm{C}$, which also falls into the operating temperature range of the $\mathrm{SCO}_{2}$ Brayton cycle. However, the corrosion behavior of the ternary salt is less known. The hygroscopic nature of the $\mathrm{MgCl}_{2}$ component complicates the investigation because dehydration of the $\mathrm{MgCl}_{2}$-containing salt is not as simple as heating up the mixture to different temperatures to remove different forms of $\mathrm{MgCl}_{2}$ hydrates. The hygroscopic nature of $\mathrm{MgCl}_{2}$ has been known for a long time in the literature. ${ }^{1-9}$ Stepwise dehydration of $\mathrm{MgCl}_{2} \cdot 6 \mathrm{H}_{2} \mathrm{O}$ to form lower hydrates can be achieved by heating $\mathrm{MgCl}_{2} \cdot 6 \mathrm{H}_{2} \mathrm{O}$ to different temperatures as shown by eqn (1a)-(1d). ${ }^{4}$

$$
\mathrm{MgCl}_{2} \cdot 6 \mathrm{H}_{2} \mathrm{O}=\mathrm{MgCl}_{2} \cdot 4 \mathrm{H}_{2} \mathrm{O}+2 \mathrm{H}_{2} \mathrm{O} \text { at } \sim 117^{\circ} \mathrm{C}
$$

National Renewable Energy Laboratory, 15013 Denver West Parkway, Golden, CO 80401, USA. E-mail: Youyang.zhao@nrel.gov

$$
\begin{gathered}
\mathrm{MgCl}_{2} \cdot 4 \mathrm{H}_{2} \mathrm{O}=\mathrm{MgCl}_{2} \cdot 2 \mathrm{H}_{2} \mathrm{O}+2 \mathrm{H}_{2} \mathrm{O} \text { at } \sim 180{ }^{\circ} \mathrm{C} \\
\mathrm{MgCl}_{2} \cdot 2 \mathrm{H}_{2} \mathrm{O}=\mathrm{MgCl}_{2} \cdot \mathrm{H}_{2} \mathrm{O}+\mathrm{H}_{2} \mathrm{O} \text { at } \sim 240{ }^{\circ} \mathrm{C} \\
\mathrm{MgCl}_{2} \cdot \mathrm{H}_{2} \mathrm{O}=\mathrm{MgCl}_{2}+\mathrm{H}_{2} \mathrm{O} \text { at } \sim 400{ }^{\circ} \mathrm{C}
\end{gathered}
$$

However, hydrolysis reactions during dehydration to form $\mathrm{MgOHCl}$ and $\mathrm{HCl}$, as shown in eqn (2a) and (2b), occur simultaneously in a similar temperature range (of $>240{ }^{\circ} \mathrm{C}$ ) as dehydration: $:^{3-5,8,10,11}$

$$
\begin{gathered}
\mathrm{MgCl}_{2} \cdot 2 \mathrm{H}_{2} \mathrm{O}=\mathrm{MgOHCl}+\mathrm{HCl}(\mathrm{g})+\mathrm{H}_{2} \mathrm{O} \\
\mathrm{MgCl}_{2}+\mathrm{H}_{2} \mathrm{O}=\mathrm{MgOHCl}+\mathrm{HCl}(\mathrm{g}) .
\end{gathered}
$$

It is very challenging to control the formation of $\mathrm{MgOHCl}$ during dehydration in a normal atmosphere. Dry $\mathrm{HCl}$ gas with partial pressure exceeding values calculated by Kipouros and Sadoway ${ }^{4}$ can inhibit the hydrolysis reactions based on Le Chatelier's principle. During production of the chloride salt electrolyte for $\mathrm{Mg}$ production at Israel Chemicals Ltd (ICL), $\mathrm{Cl}_{2}$ gas is bubbled through the molten DC in a process used by ICL for controlled dehydration. At high temperatures of $533-555^{\circ} \mathrm{C}$, $\mathrm{MgOHCl}$ thermally decomposes to form $\mathrm{MgO}$ and $\mathrm{HCl}$ gas as shown in eqn (3)., ${ }^{412}$

$$
\mathrm{MgOHCl}=\mathrm{MgO}+\mathrm{HCl}(\mathrm{g})
$$

From eqn (2) and (3), both the formation and thermal decomposition of $\mathrm{MgOHCl}$ lead to formation of highly corrosive $\mathrm{HCl}$ gas. Combined with the $\mathrm{H}_{2} \mathrm{O}$ released during dehydration, $\mathrm{HCl}$ can be detrimental to most alloy components. In addition, dissolved $\mathrm{MgOHCl}$ in molten chlorides, in the form of $\mathrm{MgOH}^{+}$, is also known to corrode alloys, as given by eqn (4a) and (4b), ${ }^{13}$ 
where $\mathrm{M}$ can be a pure metal or a metal component in an alloy such as $\mathrm{Fe}, \mathrm{Cr}$, or $\mathrm{Mn}$ :

$$
\begin{gathered}
\mathrm{MgOHCl}=\mathrm{MgOH}^{+}+\mathrm{Cl}^{-} \\
x \mathrm{MgOH}^{+}+\mathrm{M}=x \mathrm{MgO}+\mathrm{M}^{x+}+(x / 2) \mathrm{H}_{2}
\end{gathered}
$$

Therefore, an effective method is needed to remove $\mathrm{MgOHCl}$ from the chloride salt before performing corrosion.

By leveraging the experience from the magnesium production industry, which has been using similar $\mathrm{MgCl}_{2}$-containing salt for decades, and from past research in the literature, ${ }^{4,14}$ we designed a thermal and chemical purification procedure that is effective at removing $\mathrm{MgOHCl}$ and other cationic impurities in the commercial salt. 100 hour corrosion evaluation at $800{ }^{\circ} \mathrm{C}$ was performed on Haynes 230, which is of interest to Gen3 CSP technology to serve as the solar-receiver material because of its high temperature stability and chemical resistance. DC salts subjected to different purifications were used for corrosion evaluation while their pre-corrosion $\mathrm{MgOHCl}$ content was tracked by an analytical titration technique. ${ }^{15}$ The objectives of our study are to (1) understand the corrosiveness of the ternary chloride salt, (2) investigate the effectiveness of each purification process, (3) verify that $\mathrm{MgOHCl}$ is indeed correlated to corrosion, and (4) design future corrosion mitigation strategies.

\section{Materials and methods}

\section{Materials}

The salt used for corrosion was "dehydrated" carnallite supplied by ICL. The primary chemical constituents of DC are $\mathrm{KCl}$ and $\mathrm{MgCl}_{2}$ in a chemical formula of $\mathrm{KMgCl}_{3}$, whose mineralogical name is carnallite. There is an additional 5$7 \mathrm{wt} \%$ of $\mathrm{NaCl}$ in the DC based on the mineralogical resource from the Dead Sea where ICL is located. Table 1 shows the elemental composition of DC provided by ICL. Note that DC salt contains roughly $5 \mathrm{wt} \%$ water (in the form of chemical hydrate and/or physically absorbed moisture). Once received, the DC salt was stored in an MBraun glove box under nitrogen with $<0.5 \mathrm{ppm} \mathrm{H}_{2} \mathrm{O}$ and $<0.5 \mathrm{ppm} \mathrm{O}_{2}$.

\section{Salt purification}

The dehydrated carnallite salt was purified to remove $\mathrm{H}_{2} \mathrm{O}$ and impurities before being used for corrosion with Haynes 230 coupons at $800 \pm 10^{\circ} \mathrm{C}$ for 100 hours. Salt purification consists of two separate parts: a thermal purification and a chemical purification. The thermal purification follows the principles of Kipouros and Sadoway, ${ }^{4}$ which provides the guideline for a stepwise dehydration process at $117^{\circ} \mathrm{C}$ for 8 hours, $180^{\circ} \mathrm{C}$ for 8 hours, $240{ }^{\circ} \mathrm{C}$ for 2 hours, $400{ }^{\circ} \mathrm{C}$ for 1 hour, and $600{ }^{\circ} \mathrm{C}$ for 1

Table 1 Carnallite elemental chemical analysis provided by ICL

\begin{tabular}{cccccc}
\hline $\mathrm{K} w \mathrm{t} \%$ & $\mathrm{Mg}$ wt\% & $\mathrm{Na}$ wt\% & $\mathrm{Brwt} \%$ & $\mathrm{Cl} \mathrm{wt} \%$ & $\mathrm{H}_{2} \mathrm{O}$ wt\% \\
\hline 21.2 & 12.8 & 1.33 & 0.58 & 58.2 & 5
\end{tabular}

Fig. 1 Schematic showing the dimension of the machined Haynes 230
coupons used for corrosion where $L$ is the length, $W$ is the width, and $D$
is the thickness of the coupons. A hole of $4 \mathrm{~mm}$ diameter is cut to allow
the coupon to be hung on a Ni wire.

Fig. 1 Schematic showing the dimension of the machined Haynes 230
coupons used for corrosion where $L$ is the length, $W$ is the width, and $D$
is the thickness of the coupons. A hole of $4 \mathrm{~mm}$ diameter is cut to allow
the coupon to be hung on a Ni wire.

Fig. 1 Schematic showing the dimension of the machined Haynes 230
coupons used for corrosion where $L$ is the length, $W$ is the width, and $D$
is the thickness of the coupons. A hole of $4 \mathrm{~mm}$ diameter is cut to allow
the coupon to be hung on a Ni wire.

Fig. 1 Schematic showing the dimension of the machined Haynes 230
coupons used for corrosion where $L$ is the length, $W$ is the width, and $D$
is the thickness of the coupons. A hole of $4 \mathrm{~mm}$ diameter is cut to allow
the coupon to be hung on a Ni wire.

hour, with a heating rate of $5{ }^{\circ} \mathrm{C} \mathrm{min}^{-1}$ between the isothermal steps. The chemical purification follows the principles of using an active metal such as $\mathrm{Mg}$ or $\mathrm{Zr}$ to remove $\mathrm{MgOHCl}$ impurity as given by the German Aerospace Center (DLR) and Savannah River National Laboratory (SRNL). ${ }^{13,16,17}$ Following SRNL's suggestion based on their investigation, we used $1.7 \mathrm{wt} \%$ of elemental $\mathrm{Mg}$ chips (99.98\% trace metals basis, 6-35 mesh, Sigma Aldrich). $1.7 \mathrm{wt} \%$ of $\mathrm{Mg}$ was a conservative estimation to ensure $\mathrm{Mg}$ is in excess. Investigation of a more accurate amount of $\mathrm{Mg}$ addition was determined in a follow-up study. After chemical purification, excess $\mathrm{Mg}$, in the form of droplets at the bottom of the solidified salt, was removed.

\section{Corrosion setup}

Haynes 230 supplied by Haynes International was cut by a waterjet cutter into coupons with dimensions shown in Fig. 1. The coupon surfaces were lightly polished with 120-grit sandpaper in water prior to corrosion tests. A $250 \mathrm{~mL}$ Ni crucible (Sigma-Aldrich Z246581) and a Ni crucible cover (Sigma-Aldrich Z245700) were used as the corrosion vessel. The crucible and cover were used as received without special treatment. Three Haynes 230 coupons were used in each corrosion test. A 4 mm-diameter hole was drilled at the center of the Ni crucible cover to form a mechanism to hang the Haynes coupons on a Ni wire $(99.98 \%, 1 \mathrm{~mm}$ diameter, Goodfellow NI005171) into the molten chloride salt. The schematic in Fig. 2 shows the details of the corrosion vessel setup. We used a combination of alumina tube $(3.08 \mathrm{~mm}$ outer diameter, $1.53 \mathrm{~mm}$ inner diameter, CoorsTek), alumina plate ( $2 \mathrm{~mm}$ thickness, CoorsTek), and quartz disc $(25.4 \mathrm{~mm}$ diameter with a 3.2 mm-diameter center hole, AdValue Technology FQ-D-1N-N1/16) to prevent galvanic coupling between Haynes 230 coupons and the $\mathrm{Ni}$ crucible/cover. The spacing between Haynes 230 coupons was about $1 \mathrm{~cm}$ to allow ample space to minimize mass-transfer limitation during corrosion testing.

About $200 \mathrm{~g}$ of purified DC salt (after removal of excess $\mathrm{Mg}$ droplets) were placed into the Ni crucible. This amount of salt ensured full submersion of the Haynes 230 coupons in the molten salt during corrosion. The corrosion setup was then assembled according to Fig. 2. The assembly was next placed into a stainless-

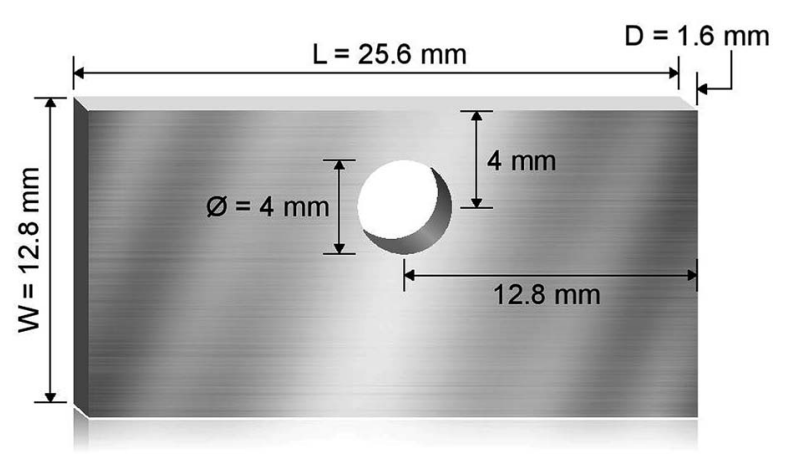




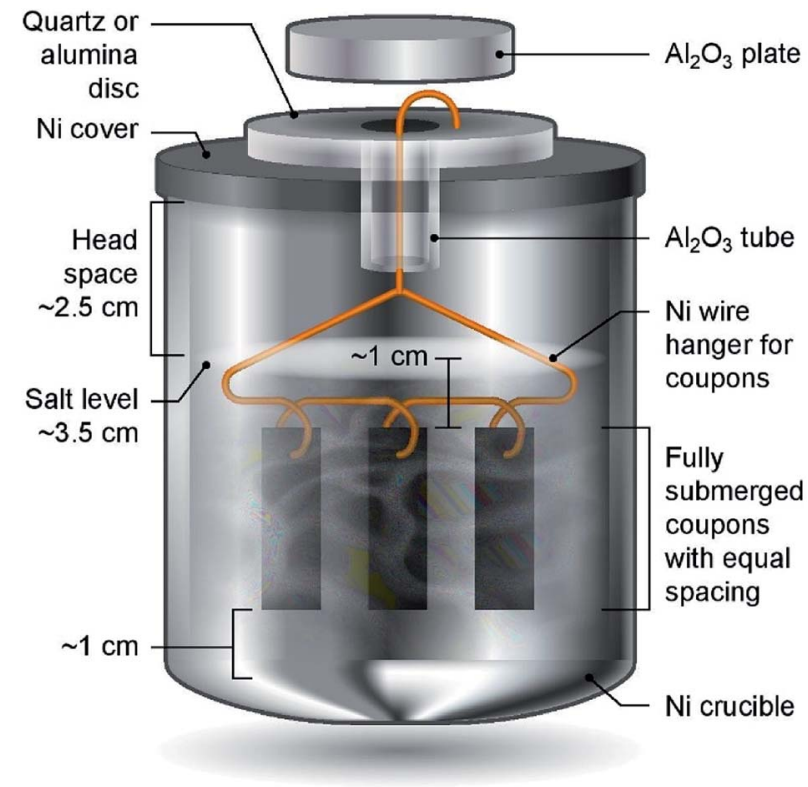

Fig. 2 Schematic of the corrosion vessel setup (not to scale) showing all components and spatial arrangement of Haynes 230 coupons and salts for corrosion tests. Mg chips are blended into the salt mixture.

steel 309 (SS 309) bag (McMaster 3438K13). A piece of Ta foil ( $0.0127 \mathrm{~mm}$ thickness, certified pinhole-free, $99.95 \%$ trace metals basis, BeanTown Chemical) was inserted into the SS bag, on top of the assembly, serving as an oxygen getter. The opening of the SS bag was folded to avoid excess release of vapor from the corrosion vessel to the furnace test vessel during the corrosion test. The entire assembly was completed in the glove box under ultra-highpurity (UHP) nitrogen atmosphere and then transferred into the furnace test vessel within a few minutes. The furnace test vessel was sealed from ambient atmosphere with a grafoil gasket. The furnace test vessel was pumped down to $-0.08 \mathrm{MPa}$ and refilled with nitrogen gas (UHP, Airgas) at least three times to remove oxygen and moisture, after which UHP nitrogen gas was flowed continuously at $150 \mathrm{sccm}$ during corrosion. The heating schedule shown in Table 2 was used for the corrosion.

Post-corrosion sample preparation: after corrosion testing, the assembly was transferred to the glove box and the corroded Haynes 230 coupons were carefully retrieved after breaking the solidified salt. Next, the Haynes 230 coupons were taken out of the glove box, immersed in deionized (DI) water, and ultrasonicated for $15 \mathrm{~min}$ to remove residual salt. After ultrasonication, the coupons were rinsed with ethanol, dried, and stored in a desiccator. The coupons were cut by a diamond-blade

Table 2 Heating schedule for the 100 hour corrosion test at $800^{\circ} \mathrm{C}$ Salt temperature range, ${ }^{\circ} \mathrm{C} \quad$ Ramp rate, ${ }^{\circ} \mathrm{C}$ min ${ }^{-1} \quad$ Hold time, hour

25-117

117-800

800-25
5

Natural cooling
8

100

Not applicable saw about 6-7 $\mathrm{mm}$ from the short edge. The cut surface was mounted in phenolic resin and polished to a mirror finish for metallographic characterization with scanning electron microscopy (SEM) and energy-dispersive spectroscopy (EDS).

\section{Corrosion rate calculation}

The corrosion rate $C_{1}$ defined as the loss of metal surface thickness per unit time (e.g., $\mu$ m per year) is given by eqn (5) based on the initial metal-coupon surface area $(A)$, the weight change of the metal coupons during corrosion test $(\Delta W)$, corrosion time $(t)$, and metal density $(\rho)$ assuming that uniform corrosion occurred on the Haynes 230 coupons and that there was no change of corrosion mechanism(s).

$$
C_{1}=\Delta W / \rho A t
$$

\section{MgOHCl content measurement}

An analytical titration technique was developed at NREL. ${ }^{15}$ This titration method used the different solubilities and chemical reactions of chloride salt components, $\mathrm{MgOHCl}$ and $\mathrm{MgO}$, in DI water and methanol to have successful physical separation of each species, followed by an ethylenediaminetetraacetic acid (EDTA) titration to determine $\mathrm{Mg}^{2+}$ content in each species. The method was able to detect $\mathrm{MgOHCl}$ content down to at least $0.1 \mathrm{wt} \%$ with standard deviation on the order of $0.01 \mathrm{wt} \%$ as reported by NREL. ${ }^{15}$

\section{Results}

\section{MgOHCl content}

Fig. 3 shows the $\mathrm{MgOHCl}$ content measured by the analytical titration method. There is a gradual increase of $\mathrm{MgOHCl}$ during the first four isotherms of the thermal purification (i.e., $117^{\circ} \mathrm{C}$,

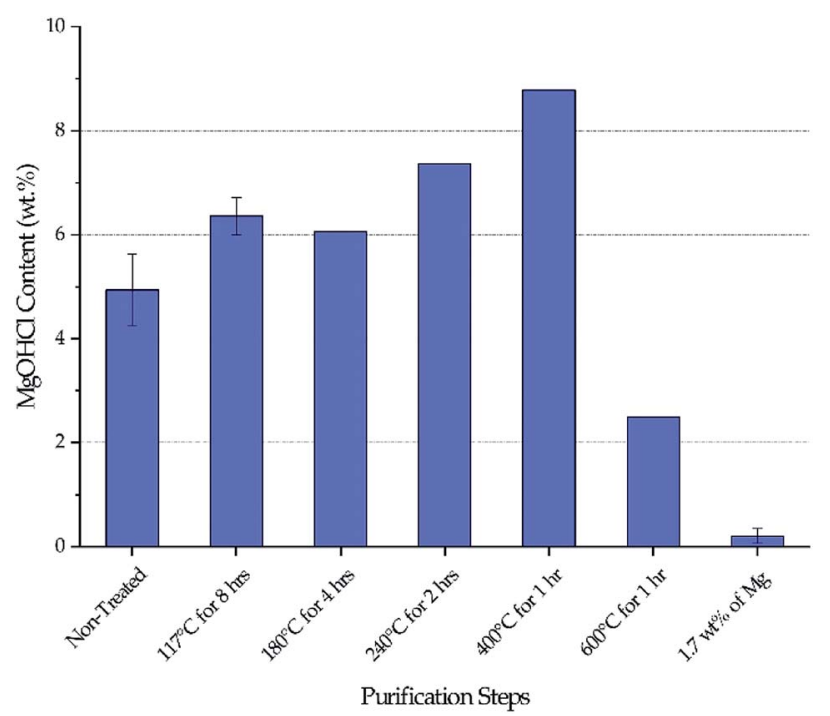

Fig. 3 Variation of $\mathrm{MgOHCl}$ during thermal purification and chemical purification with $1.7 \mathrm{wt} \%$ of $\mathrm{Mg}$ chips. The same batch of salt was used to obtain data at different purification steps. Error bars are present when multiple measurements were available. 
$180{ }^{\circ} \mathrm{C}, 240{ }^{\circ} \mathrm{C}$, and $400{ }^{\circ} \mathrm{C}$ ), followed by a sharp drop at the last isotherm of the thermal purification (i.e., $600{ }^{\circ} \mathrm{C}$ ). The $\mathrm{MgOHCl}$ content further drops during the chemical purification (i.e., with 1.7 wt $\%$ of $\mathrm{Mg}$ ). It should be noted that multiple measurements were performed on non-treated DC salt, DC salt after heat treatment at $117{ }^{\circ} \mathrm{C}$ for 8 hours, and thermally + chemically purified salt (i.e., $1.7 \mathrm{wt} \%$ of $\mathrm{Mg}$ ).

Our major objective is to detect the decrease of $\mathrm{MgOHCl}$ content by the thermal + chemical purification, so we focused our titration effort on the thermally/chemically purified salt sample (1.7 wt\% of $\mathrm{Mg}$ in Fig. 3). We did not perform multiple titrations on every salt sample because the existing data suggested that the standard deviation of the titration measurements was at a fairly small level of less than $0.5 \mathrm{wt} \%$. Nevertheless, we acknowledge that more measurements should have been performed to have standard deviation information. Hence, only qualitative (instead of quantitative) analysis of the data is given in the following Discussion section.

\section{Corrosion rates}

Fig. 4 shows the corrosion rates of Haynes 230 coupons in molten DC salts at $800 \pm 10{ }^{\circ} \mathrm{C}$ for 100 hours after different purifications were performed on DC salt following the procedures outlined in the Experimental section. The standard deviation reported in Fig. 4 was based on at least three coupons for each salt treatment (i.e., non-treated, thermal, and thermal + chemical). Positive corrosion rate is defined as mass loss. Experimental corrosion tests were attempted on non-treated DC, but no results were obtained successfully because the extremely high corrosivity of the non-treated DC caused substantial damage of the experimental setup, e.g., leakage of the furnace vessel. Hence, we did not believe that the results could be used. Instead, the corrosion rate in non-treated DC salt could only be estimated based on the fact that the maximum amount of $\mathrm{MgOHCl}$ that the non-treated DC can generate (i.e., 8-9 wt\% after $400{ }^{\circ} \mathrm{C}$ in Fig. 3) is more than 3 times that for the thermally purified DC (i.e., $\sim 2.5 \mathrm{wt} \%$ after $600{ }^{\circ} \mathrm{C}$ in Fig. 3 ). If we

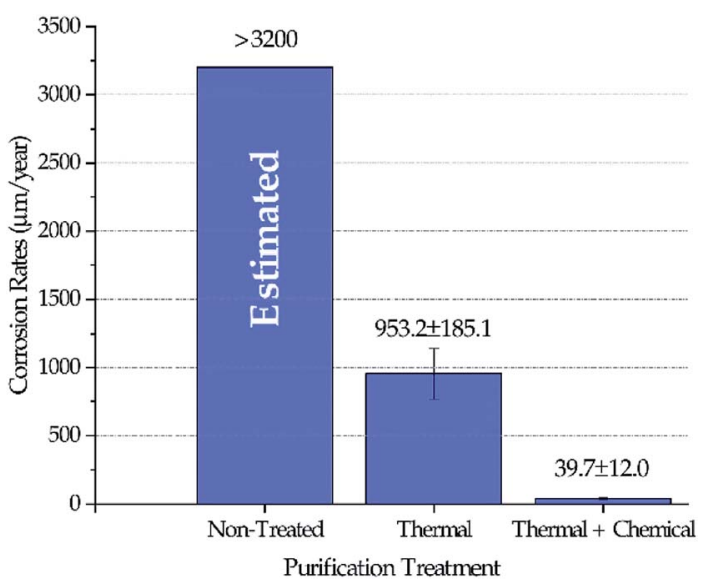

Fig. 4 Corrosion rates of Haynes 230 coupons in molten DC salts at $800 \pm 10^{\circ} \mathrm{C}$ for 100 hours following different purification treatments. Corrosion rate in non-treated DC salt was estimated at $3200 \mu \mathrm{m}$ per year or above. assume that corrosion is roughly linearly correlated to the amount of $\mathrm{MgOHCl}$, then, for first approximation, it is estimated that non-treated DC will produce a corrosion rate of 3200 $\mu \mathrm{m}$ per year or above. It should be noted that corrosion rates based on conversion from mass loss instead of direct measurement of corrosion thickness is used here because (1) intergranular corrosion is commonly seen in metals corroded by molten chlorides which makes it difficult to define such thickness, and (2) the high corrosion rates of "Thermal" in Fig. 4 should not support a build-up layer of corrosion products based on an unpublished study on similar molten chlorides by the same authors. However, for low corrosion rates such as the one reported for "Thermal + Chemical", it should be cautious to solely rely on mass losses to determine corrosion rates. We acknowledge that there can be errors associated with the growth of corrosion products at the corrosion interface. Our best estimated error for the "Thermal + Chemical" is up to $40 \mu \mathrm{m}$ per year based on the most likely type of corrosion product (e.g., $\mathrm{MgO}$ ) and its thickness (e.g., less than $5 \mu \mathrm{m}$ ).

\section{Salt chemistry analysis}

Inductively coupled plasma (ICP)-mass spectroscopy (MS)/ optical emission spectroscopy (OES) was used to measure the elemental composition of the cationic impurities present in the non-treated, thermally purified, and chemically purified DC salts (Table 3). Fe, Cr, Mn, and Ni were found to be the major cationic species, in addition to the major salt components of $\mathrm{Mg}, \mathrm{K}$, and $\mathrm{Na}$ (see Table 1). The increase of $\mathrm{Fe}, \mathrm{Cr}, \mathrm{Mn}$, and $\mathrm{Ni}$ (i.e., major metallic components of stainless steel) after thermal purification is attributed to contamination from the stainlesssteel furnace test vessel because corrosion products between salt vapor/HCl vapor and furnace test vessel-especially those formed on the test vessel cap directly above the purification crucible-could drop back into the salt, thus causing contamination. To clarify, salt purification did not use the same setup as the corrosion setup (shown in Fig. 2). An open crucible without a cover was used. Thus, contamination could have occurred and contributed to the increase of $\mathrm{Fe}, \mathrm{Cr}, \mathrm{Mn}$, and $\mathrm{Ni}$.

\section{Discussion}

The decrease of $\mathrm{MgOHCl}$ content from $\sim 5 \mathrm{wt} \%$ in non-treated salt to $\sim 2.5 \mathrm{wt} \%$ in thermally purified salt and to $<0.5 \mathrm{wt} \%$ in both thermally and chemically purified salt, as shown in Fig. 3, agrees with the decrease of corrosion rate in the corresponding salt, as shown in Fig. 4. This suggests that $\mathrm{MgOHCl}$ can be used as a good indicator of the corrosiveness of the molten salt. It has

Table 3 ICP-MS/OES results on non-treated, thermally purified, and thermally/chemically purified DC salts

\begin{tabular}{lllll}
\hline Salt Treatment & Fe ppm & Cr ppm & Mn ppm & Ni ppm \\
\hline Non-treated & 31 & 17 & 3 & 1 \\
After thermal & 7018 & 327 & 166 & 1112 \\
After thermal/chemical & 394 & 120 & 39 & 8
\end{tabular}


been known from literature ${ }^{\mathbf{1 6 , 1 8 - 2 0}}$ that intergranular attack of $\mathrm{Cr}$ by $\mathrm{MgOH}^{+}$is a common corrosion mechanism in heavily corroded Ni-Fe-Cr alloys such as in the case of the non-treated salt (estimated at $>3200 \mu \mathrm{m}$ per year) and thermally purified salt ( $\sim 950 \mu \mathrm{m}$ per year). When an active metal such as $\mathrm{Mg}$ is added into the molten chloride, intergranular corrosion can be significantly reduced, as shown by Ding et al. ${ }^{21}$ who investigated corrosion of Hastelloy C-276 (C276) at $700{ }^{\circ} \mathrm{C}$ in a ternary $\mathrm{MgCl}_{2}-\mathrm{KCl}-\mathrm{NaCl}$ (60-20-20 mol\%) made from commercial $\mathrm{NaCl}, \mathrm{KCl}$, and $\mathrm{MgCl}_{2}$ with $1 \mathrm{wt} \%$ of elemental $\mathrm{Mg}$ addition. The corrosion rate of the $\mathrm{C} 276$ alloy in Ding et al. $(29.8 \pm 8.7 \mu \mathrm{m}$ per year) is very close to that of the Haynes 230 corroded in the thermally and chemically purified salt (at $800{ }^{\circ} \mathrm{C}$ ) in this work. Given the similarity in salt condition and final corrosion rate, it is expected that intergranular corrosion has also been effectively controlled in this work.

Therefore, for Gen3 CSP that aims to use $\mathrm{MgCl}_{2}$-containing molten chlorides as HTF and TES to reach a desired 30 year lifespan, it is critical to purify the molten chlorides to minimize $\mathrm{MgOHCl}$ content as well as the detrimental intergranular corrosion.

\section{Effect of thermal purification}

Stepwise heating of DC salt at the specified isothermal temperatures is proven to be effective at purifying the salt given the drop of $\mathrm{MgOHCl}$ content from a maximum of $8-9 \mathrm{wt} \%$ in non-treated DC to $\sim 2.5 \mathrm{wt} \%$ in thermally purified DC (i.e., after $600{ }^{\circ} \mathrm{C}$ ), as shown in Fig. 3. (Note that the initial $\mathrm{MgOHCl}$ was $\sim 5 \mathrm{wt} \%$ in non-treated $\mathrm{DC}$; but the increase of $\mathrm{MgOHCl}$ due to hydrolysis of $\mathrm{MgCl}_{2}$ during heat treatment must also be taken into account.) This 3- to 4-fold drop in $\mathrm{MgOHCl}$ content leads our hypothesis that a significant reduction in corrosion should occur-by comparing the estimated corrosion of non-treated salt to that of the thermally purified salt.

The variation of $\mathrm{MgOHCl}$ content during thermal purification also qualitatively corroborates the literature understanding of the chemical changes occurring in hydrated $\mathrm{MgCl}_{2}$ system. Hydrolysis of anhydrous $\mathrm{MgCl}_{2}$ or $\mathrm{MgCl}_{2} \cdot 2 \mathrm{H}_{2} \mathrm{O}$ to form $\mathrm{MgOHCl}$ can occur in the temperature range of $210-445{ }^{\circ} \mathrm{C} .{ }^{\mathbf{8}, 10}$ Our measured $\mathrm{MgOHCl}$ content indeed shows two increases at the isothermal temperature of $240{ }^{\circ} \mathrm{C}$ and $400{ }^{\circ} \mathrm{C}$, which suggest that some $\mathrm{MgCl}_{2}$ molecules in DC salt are in the form of $\mathrm{MgCl}_{2} \cdot 2 \mathrm{H}_{2} \mathrm{O}$ and $\mathrm{MgCl}_{2} \cdot \mathrm{H}_{2} \mathrm{O}$ because $240{ }^{\circ} \mathrm{C}$ and $400{ }^{\circ} \mathrm{C}$ are the corresponding dehydration temperatures, respectively. The variation among non-treated $\mathrm{DC}$ at $117{ }^{\circ} \mathrm{C}$ and $180{ }^{\circ} \mathrm{C}$ may be attributed to inherent inconsistency of salt samples considering the magnitude of the available error bars. The decrease of $\mathrm{MgOHCl}$ at $600{ }^{\circ} \mathrm{C}$ is the result of $\mathrm{MgOHCl}$ thermal decomposition, which is shown to occur at a temperature as low as $415{ }^{\circ} \mathrm{C} .{ }^{8,10}$ The thermodynamically predicted onset temperature for $\mathrm{MgOHCl}$ thermal decomposition is $555^{\circ} \mathrm{C}$ by Kipouros and Sadoway ${ }^{4}$ and $568{ }^{\circ} \mathrm{C}$ as calculated by FactSage. ${ }^{22}$

\section{Effect of metallic $\mathrm{Mg}$ during chemical purification}

Addition of active metals such as $\mathrm{Mg}$ or $\mathrm{Zr}$ can reduce $\mathrm{MgOHCl}$, as proposed by SRNL. The Ellingham diagram in chloride systems $^{23}$ (Fig. 5) gives the Gibbs free energy of formation $\Delta G_{\mathrm{f}}$ for different cations, which predicts the following: to remove the major metallic impurities such as Fe cations in the DC salt, one needs to use a metal that forms a more stable cation in the chloride system (i.e., with a more negative $\Delta G_{\mathrm{f}}$ ). At the same time, the metal cation cannot be more stable than the major constituents of the salt (i.e., $\mathrm{Na}^{+}, \mathrm{K}^{+}$, and $\mathrm{Mg}^{2+}$ ); otherwise, we will lose these salt components (i.e., metallic $\mathrm{Ca}$ and Li should not be used). Fig. 5 then predicts that $\mathrm{Zn}, \mathrm{Zr}$, and $\mathrm{Mg}$ are good candidates for this purpose from the thermodynamic perspective. $\mathrm{Mg}$ was selected over $\mathrm{Zn}$ and $\mathrm{Zr}$ because it does not introduce other elements into the ternary $\mathrm{MgCl}_{2}-\mathrm{KCl}-\mathrm{NaCl}$ salt system. As shown in Table 3, the concentrations of Fe, Cr, Mn, and Ni decrease significantly in the thermally/chemically purified salt compared to thermally purified salt. Note that Fe, Cr, $\mathrm{Mn}$, and Ni cations are all less thermodynamically stable than $\mathrm{Mg}$ cation, as shown in Fig. 5. Although the absolute magnitude of $\mathrm{Fe}, \mathrm{Cr}, \mathrm{Mn}$, and $\mathrm{Ni}$ after thermal/chemical purification was not as low as expected (primarily due to contamination, as explained in the Experimental section), these substantial decreases indeed prove that elemental $\mathrm{Mg}$ is able to remove these cations from the salt. A follow-up study (publication in preparation) showed that the concentrations of $\mathrm{Fe}, \mathrm{Cr}, \mathrm{Mn}$, and $\mathrm{Ni}$ can be reduced to less than $10 \mathrm{ppm}$. In a separate purification experiment using an alternative chloride salt with $\mathrm{Ca}$ and $\mathrm{Li}$ impurities, chemical purification with $\mathrm{Mg}$ is not able to reduce their content, which also agrees with thermodynamic prediction.

\section{Metallic Mg as corrosion potential control}

Metallic $\mathrm{Mg}$ is known to provide cathodic protection to metal alloys in molten chlorides where $\mathrm{Mg}$ serves as a sacrificial anode. ${ }^{16,17,19}$ It is generally accepted that Cr leaching is the major corrosion mechanism of Cr-containing alloys in molten chlorides. ${ }^{16,17,19,20,24}$ Past work from SRNL ${ }^{16,17}$ showed that without $\mathrm{Mg}$, the corrosion potential of a $\mathrm{Fe}-\mathrm{Ni}-\mathrm{Cr}$ alloy is higher than that of $\mathrm{CrCl}_{2}$ such that $\mathrm{Cr}$ in the alloy will leach and form $\mathrm{CrCl}_{2}$. Addition of $\mathrm{Mg}$ shifts the corrosion potential of the alloy by more than $0.5 \mathrm{~V}$ to be lower than that of both $\mathrm{CrCl}_{2}$ and $\mathrm{CrCl}_{3}$-meaning that $\mathrm{Cr}$ in the alloy is thermodynamically

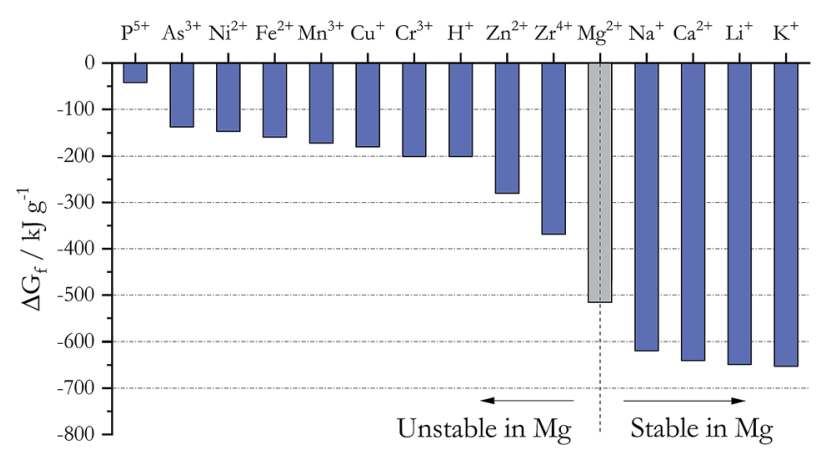

Fig. 5 Gibbs free energy of formation for different chlorides at $827^{\circ} \mathrm{C}$. The cations to the left of $\mathrm{Mg}^{2+}$ are unstable in the presence of elemental $\mathrm{Mg}$ whereas the cations to the right of $\mathrm{Mg}^{2+}$ are stable. 
stabilized. Also, adding elemental $\mathrm{Mg}$ into molten chlorides during corrosion testing also significantly reduces the corrosion current—by two orders of magnitude—of the reaction

$$
\mathrm{Cr}+2 \mathrm{Cl}^{-} \rightarrow \mathrm{CrCl}_{2}+2 \mathrm{e}^{-}
$$

which represents the major mechanism of $\mathrm{Cr}$ corrosion in $\mathrm{Cr}$ containing alloys. In this case, the oxidation reaction of metallic magnesium

$$
\mathrm{Mg} \rightarrow \mathrm{Mg}^{2+}+2 \mathrm{e}^{-}
$$

provides the majority of the anodic current (rather than that provided by the reaction given by eqn (6)), which balances the cathodic current provided by the following reaction:

$$
\mathrm{CrCl}_{3}+\mathrm{e}^{-} \rightarrow \mathrm{CrCl}_{2}+\mathrm{Cl}^{-}
$$

The anodic current of reaction in eqn (6), which is directly related to the corrosion of $\mathrm{Cr}$ in metal alloys, is lowered; so, addition of elemental $\mathrm{Mg}$ should reduce $\mathrm{Cr}$ leaching.

\section{Metallic $\mathrm{Mg}$ to facilitate oxygen scavenging}

In addition to its use as potential control of corrosion, elemental $\mathrm{Mg}$ has a second use to promote oxygen scavenging. Based on eqn (4b), elemental $\mathrm{Mg}$ can reduce $\mathrm{MgOH}^{+}$and form $\mathrm{MgO}$ and $\mathrm{H}_{2}$ :

$$
2 \mathrm{MgOH}^{+}+\mathrm{Mg}=\mathrm{Mg}^{2+}+2 \mathrm{MgO}+\mathrm{H}_{2}
$$

The fundamental cause of $\mathrm{MgOH}^{+}$(or $\mathrm{MgOHCl}$ ) formation is the reaction of $\mathrm{MgCl}_{2}$ with water (and oxygen) in the chloride salt as shown by eqn (2a) and (2b). These soluble $\mathrm{MgOH}^{+}$ions then carry the oxygen atoms from water and become reactive with components in the alloy such as $\mathrm{Cr}, \mathrm{Mn}$, and Fe (eqn (4b)). After purification, $\mathrm{MgO}$ carries over the oxygen from $\mathrm{MgOH}^{+}$as one of the purification products. The low solubility of $\mathrm{MgO}$ in molten chloride $\left(<0.2 \mathrm{wt}^{25,26}\right)$ suggests that these oxygen atoms, once carried by MgO molecules, should be a minor source of corrosiveness. Eqn (9) then suggests that elemental $\mathrm{Mg}$ promotes the reaction of oxygen scavenging during the initial salt purification stage by transforming the most detrimental oxygen-containing species in the molten salt, i.e., soluble $\mathrm{MgOH}^{+}$, to $\mathrm{MgO}$. It also suggests that the presence of $\mathrm{Mg}$ in the molten salt is important for continued protection of the metal alloys against corrosion as oxygen and moisture ingress (e.g., through flanges and valves) can form more $\mathrm{MgOH}^{+}$, which is expected during normal CSP plant operation.

The photo in Fig. 6 shows a dark sludge phase formed at the bottom of the chloride salt after chemical purification with $\mathrm{Mg}$. The sludge was dissolved in DI water to remove residual chloride salt and filtered through a $450 \mathrm{~nm}$ filter paper. The collected particles were analyzed by X-ray diffraction. Fig. 7 shows that the collected particles in the sludge phase were identified as predominantly $\mathrm{MgO}$. The main diffraction peaks at $2 \theta$ values of $42.8^{\circ}, 62.2^{\circ}, 78.5^{\circ}, 36.8^{\circ}, 109.6^{\circ}, 74.6^{\circ}$, and $93.9^{\circ}$ are attributed to the MgO's crystal orientations of (200), (220), (222), (111), (420), (311) and (400), respectively (JCPDS card no. 45-

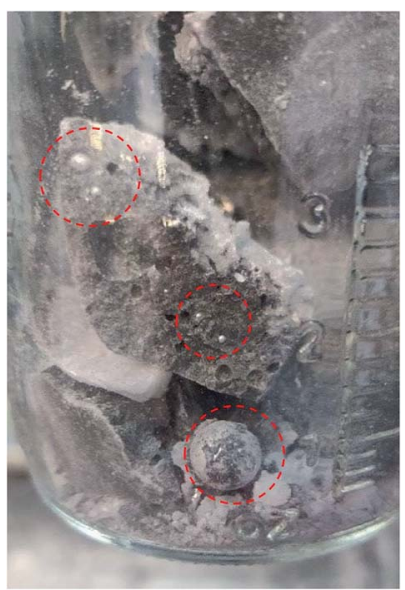

Fig. 6 Photo showing the dark sludge phase formed at the bottom of the salt after chemical purification of $\mathrm{Mg}$. The excess $\mathrm{Mg}$ droplets are circled in red.

0946 and known literature ${ }^{27-29}$ ). Only two peaks around $2 \theta$ of 43$45^{\circ}$ and one minor peak around $2 \theta$ of $51^{\circ}$ cannot be attributed to $\mathrm{MgO}$. The XRD result confirms the effectiveness of $\mathrm{Mg}$ to promote oxygen scavenging as shown in eqn (9) because reduction of $\mathrm{MgOHCl}$ by $\mathrm{Mg}$ is the major chemical pathway to form a significant amount of $\mathrm{MgO}$ particles. Thermal decomposition of $\mathrm{MgOHCl}$ to form $\mathrm{MgO}$ (eqn (3)) alone is not able to produce such a large quantity of $\mathrm{MgO}$ because the amount of sludge produced after thermal purification was found to be smaller. $\mathrm{MgO}$ formation also indicates that $\mathrm{Mg}$ is a consumable during the purification process. Therefore, in the future, we need to investigate how much and how frequently $\mathrm{Mg}$ should be replenished if oxygen and moisture ingress in the CSP plants is inevitable.

\section{Amount of $\mathrm{Mg}$ added during chemical purification}

$1.7 \mathrm{wt} \%$ of metallic Mg used during chemical purification (the specific amount was provided by SRNL to NREL) is

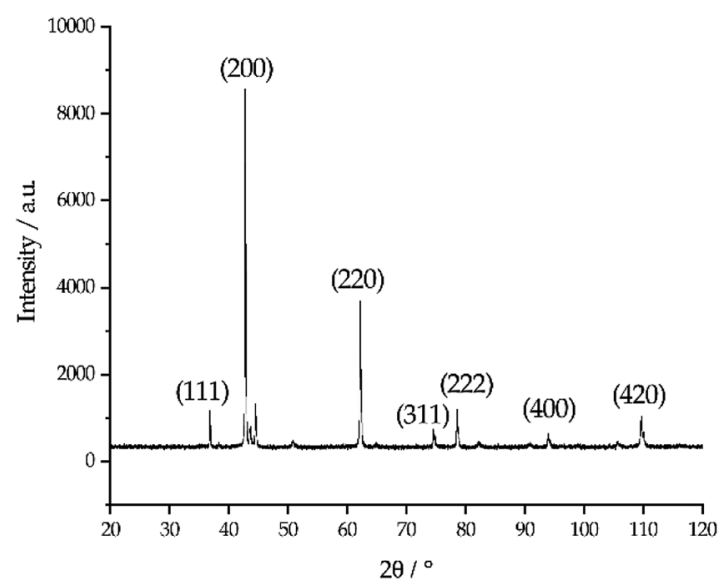

Fig. 7 X-ray diffraction pattern of the collected particles in the dark sludge phase. The numbers in the parentheses indicate the crystallographic orientations of $\mathrm{MgO}$ reference corresponding to each major diffraction peaks. 
a conservative amount to ensure that $\mathrm{Mg}$ is in absolute excess during purification and that most $\mathrm{MgOHCl}$ can be reduced to minimize the corrosiveness of the salt during corrosion testing. No optimization of the $\mathrm{Mg}$ amount has been performed. The analytical titration method measured that the $\mathrm{MgOHCl}$ content was around $2-3 \mathrm{wt} \%$ after thermal purification and before chemical purification (see Fig. 3). The stoichiometry in eqn (9) predicts that for $2-3 \mathrm{wt} \%$ of $\mathrm{MgOHCl}$, roughly $0.31-0.47 \mathrm{wt} \%$ of $\mathrm{Mg}$ should be used to ensure complete reduction of $\mathrm{MgOHCl}$. Therefore, an excess of $\mathrm{Mg}$ is expected if using $1.7 \mathrm{wt} \%$ of $\mathrm{Mg}$. Fig. 6 also proves that $1.7 \mathrm{wt} \%$ of $\mathrm{Mg}$ is in excess because droplets of $\mathrm{Mg}$ are clearly observed in the sludge phase. Therefore, $\mathrm{Mg}$ addition needs to be optimized in terms of amount, form factor, and temperature at which addition should occur. This optimization will minimize materials and processing costs because $\mathrm{Mg}$ is significantly more expensive than the salt at $>\$ 4000 /$ MT. For CSP to be cost competitive, it is essential to minimize the amount of $\mathrm{Mg}$ used during initial purification and/or plant operation.

\section{Conclusions}

This work confirmed previous literature understanding of the complex chemistry of $\mathrm{MgCl}_{2}$-containing salts and its dehydration strategy. We leveraged such knowledge and demonstrated experimentally that the corrosion rates of Haynes 230 in a $\mathrm{MgCl}_{2}-\mathrm{KCl}-\mathrm{NaCl}$ ternary chloride salt can be significantly reduced from $>3200 \mu \mathrm{m}$ per year (estimated) to about $40 \mu \mathrm{m}$ per year by (1) a thermal purification process as well as (2) a chemical purification process with $\mathrm{Mg}$ as corrosion potential control and oxygen scavenger. As shown by the correlation between $\mathrm{MgOHCl}$ content in the salt and corrosion rate at different stages of purification, $\mathrm{MgOHCl}$, or soluble $\mathrm{MgOH}^{+}$, is primarily responsible for corrosion. Therefore, the corrosion mitigation method using the thermal and chemical purification process is effective because it reduces the $\mathrm{MgOHCl}$ content by an order of magnitude to prevent corrosion due to formation of $\mathrm{HCl}$ gas and soluble $\mathrm{MgOH}^{+}$ions.

In the future, we plan to optimize the purification process, which aims at (1) reducing the total amount of elemental $\mathrm{Mg}$ added to lower the cost at industrial scale and (2) combining the thermal and chemical purification processes to reduce overall energy use.

\section{Conflicts of interest}

There are no conflicts of interest to declare.

\section{Acknowledgements}

This work was authored by the National Renewable Energy Laboratory, operated by Alliance for Sustainable Energy, LLC, for the U.S. Department of Energy (DOE) under Contract No. DEAC36-08GO28308. Funding was provided by U.S. Department of Energy Office of Energy Efficiency and Renewable Energy Solar Energy Technologies Office (Award number DE-EE00033870). The views expressed in the article do not necessarily represent the views of the DOE or the U.S. Government. The U.S. Government retains and the publisher, by accepting the article for publication, acknowledges that the U.S. Government retains a nonexclusive, paid-up, irrevocable, worldwide license to publish or reproduce the published form of this work, or allow others to do so, for U.S. Government purposes.

\section{Notes and references}

$1 \mathrm{H}$. Guan and $\mathrm{H}$. Wu, in 2011 International Conference on Electric Technology and Civil Engineering (ICETCE), 2011, pp. 5666-5669.

2 E. I. Savinkova and R. P. Lelekova, J. Appl. Chem. USSR, 1978, 51, 1453-1456.

3 A. K. Galwey and G. M. Laverty, Thermochim. Acta, 1989, 138, 115-127.

4 G. J. Kipouros and D. R. Sadoway, J. Light Met., 2001, 1, 111117.

5 S. Kashani-Nejad, K. W. Ng and R. Harris, Metall. Mater. Trans. B, 2004, 35, 405-406.

6 S. Kashani-Nejad, Oxides in the Dehydration of Magnesium Chloride Hexahydrate, PhD thesis, Department of Mining, Metals and Materials Engineering, McGill University, 2005.

7 Q.-Z. Huang, G.-M. Lu, J. Wang and J.-G. Yu, Metall. Mater. Trans. B, 2010, 41, 1059-1066.

8 H.-C. Eom, H. Park and H.-S. Yoon, Adv. Powder Technol., 2010, 21, 125-130.

9 J. de Bakker, J. Peacey and B. Davis, Can. Metall. Q., 2012, 51, 419-423.

10 Q. Huang, G. Lu, J. Wang and J. Yu, J. Anal. Appl. Pyrolysis, 2011, 91, 159-164.

$11 \mathrm{H}$. U. Rammelberg, T. Schmidt and W. Ruck, Energy Procedia, 2012, 30, 362-369.

12 S. Kashani-Nejad, K. W. Ng and R. Harris, Metall. Mater. Trans. B, 2005, 36, 153-157.

13 W. Ding, A. Bonk, J. Gussone and T. Bauer, Journal of Energy Storage, 2018, 15, 408-414.

14 L. Maksoud and T. Bauer, in 10th International Conference on Molten Salt Chemistry and Technology, Shenyang, China, 2015.

15 N. Klammer, C. Engtrakul, Y. Zhao, Y. Wu and J. Vidal, A Novel Method to Determine $\mathrm{MgO}$ And $\mathrm{MgOHCl}$ in Chloride Molten Salts, Anal. Chem., submitted.

16 B. L. Garcia-Diaz, L. Olson, M. Martinez-Rodriguez, R. Fuentes, H. Colon-Mercado and J. Gray, J. SC. Acad. Sci., 2016, 14, 11-14.

17 B. A. T. Mehrabadi, J. W. Weidner, B. Garcia-Diaz, M. Martinez-Rodriguez, L. Olson and S. Shimpalee, J. Electrochem. Soc., 2017, 164, C171-C179.

18 W. Ding, A. Bonk and T. Bauer, Front. Chem. Sci. Eng., 2018, 12, 564-576.

19 B. Mehrabadi, J. W. Weidner, B. Garcia-Diaz, M. MartinezRodriguez, L. Olson and S. Shimpalee, J. Electrochem. Soc., 2016, 163, C830-C838.

20 H. Sun, J. Wang, Z. Li, P. Zhang and X. Su, Sol. Energy, 2017, 171, 320-329. 
21 W. Ding, H. Shi, A. Jianu, Y. Xiu, A. Bonk, A. Weisenburger and T. Bauer, Sol. Energy Mater. Sol. Cells, 2019, 193, 298313.

22 C. W. Bale, E. Bélisle, P. Chartrand, S. A. Decterov, G. Eriksson, A. E. Gheribi, K. Hack, I. Jung, Y. Kang, J. Melançon, A. D. Pelton, S. Petersen, C. Robelin, J. Sangster, P. Spencer and M. Van Ende, Calphad, 2016, 54, 35-53.

23 T. B. Reed, Free Energy of Formation of Binary Compounds, MIT Press, Cambridge, MA, 1971.
24 H. Cho, J. W. Van Zee, S. Shimpalee, B. A. Tavakoli, J. W. Weidner, B. L. Garcia-diaz, M. J. Martinez-rodriguez, L. Olson and J. Gray, Corrosion, 2016, 72, 742-760.

25 M. Ito and K. Morita, Mater. Trans., 2004, 45, 2712-2718.

26 R. L. Martin and J. B. West, J. Inorg. Nucl. Chem., 1962, 24, 105-111.

27 G. Dercz, K. Prusik, L. Pajak, R. Pielaszek, J. J. Malinowski and W. Pudlo, Mater. Sci., 2009, 27, 201-207.

28 A. Maurya and N. Bhatia, Int. J. Eng. Res. Dev., 2017, 13, 1-6. 29 B. Wang, X. Xiong, H. Ren and H. Zhiyu, RSC Adv., 2017, 7, 43464-43473. 